\title{
Chord profile influence on the fatigue failure of a t-butt weld joint
}

\section{Influencia del perfil del cordón en la falla por fatiga de una unión soldada en $T$}

\author{
Nelson Arzola de la Peña ${ }^{1} \quad$ Oscar Javier Araque de los Ríos ${ }^{2}$ \\ Recibido 14 de agosto de 2013, aceptado 17 de enero de 2014 \\ Received: August 14, 2013 Accepted: January 17, 2014
}

\begin{abstract}
RESUMEN
Este artículo presenta un modelo de propagación de grieta por fatiga, para una unión soldada tipo T, realizada en placas de igual espesor. Se obtuvo la expresión para el factor de intensidad de tensiones adimensional, en función del tamaño de la grieta, para tres perfiles de cordón: recto, convexo y cóncavo. Se evidenció una razón de propagación de la grieta más pequeña para el cordón de perfil cóncavo cuando se compara con los cordones de perfiles recto y convexo. Por último, se realizó la validación del modelo de propagación mediante experimentos de fatiga en probetas no estándar, que emularon al modelo teórico, obteniéndose una correspondencia estadísticamente adecuada. Los resultados de vida de fatiga teóricos, para cada tipo de perfil de cordón, quedaron contenidos dentro del intervalo de confianza experimental [13280-21650] ciclos para 95\% de confiabilidad.
\end{abstract}

Palabras clave: Soldadura, unión en T, fatiga, predicción de fallas, mecánica de la fractura, perfil del cordón.

\section{ABSTRACT}

This paper shows a mathematical model assessment for fatigue crack propagation in a T-butt weld joint same thickness sheet. The assessment reached a closed-form solution for the dimensionless stress intensity factor expression, depending on crack size, for three types of weld chord profiles: straight, convex, and concave. It is established that crack growth rate for concave chord profile is lower than for the other two chord profiles. Finally, fatigue test in non-standard specimens were carried out to validate theoretical models. Fatigue life for all three weld chord profiles are within the experimental confidence interval [13280-21650] cycles for 95\% probability.

Keywords: Welding, T-butt weld, fatigue, failure prediction, fracture mechanics, chord profile.

\section{INTRODUCTION}

The design analytical methods used for welded joints have basically not changed in recent decades, although specialists on the issue know of the simplifications employed. To overcome for this lack of preciseness in the design of welded joints, the technical standards on welding employ high design factors to guarantee the structural integrity [1].
Different failure mechanisms operate in welded joints, but the fatigue failure is the most catastrophic because it almost never shows prior signs of the loss of functionality. Fatigue cracks stem from or emerge from internal or surface micro-defects, often enhanced by geometric stress concentration. The place where the initial micro-defects occur on the weld chord depend on a set of factors: geometric stress concentration, metallurgic characteristics,

\footnotetext{
1 Grupo de Investigación en Diseño Óptimo Multidisciplinario. Departamento de Ingeniería Mecánica y Mecatrónica. Universidad Nacional de Colombia. Bogotá, Colombia. E-mail: narzola@unal.edu.co

2 Grupo de Investigación Desarrollo Tecnológico. Departamento de Ingeniería Mecánica. Universidad de Ibagué. Ibagué, Tolima, Colombia. E-mail: oscar.araque@unibague.edu.co, ojaraque@yahoo.com.mx
} 
welding scheme, cooling rate of the weld, material properties, restrictions to the dilatation/contraction to which the material joined are subjected, among others [2-4]. These micro-defects are the seeds of subcritical propagation of the cracks when in their acute angles stress intensity factors are reached above the threshold value of propagation.

In this work, modeling of stable crack propagation was carried out and validation experiments were performed on the fracto-mechanical behavior of a welded T-butt joint. An important contribution in this work is the consideration of the type of chord profile in the fatigue life of the joint, using concave, convex, and straight profiles. A mathematical model was obtained, based on Fracture Mechanics and using the Finite Element Method as tool, which permits evaluating the crack propagation rate and the residual strength of the welded joint of structural steel obtained through Shield Metal Arc Welding (SMAW). The work seeks to increase the degree of precision in the fatigue calculation of welded joints through a crack propagation predictive model. In addition, experimental verification was carried out of the behavior of the joint's structural integrity under cyclic loads. The model obtained contributes to greater precision in calculating fatigue life and residual life for the type of geometric configuration analyzed.

\section{MATERIALS AND METHODS}

It is known that the shape of the profile of the weld chord influences on the severity of the field of stresses, being a relevant factor to consider in fatigue failure predictive models [5-6]. To analyze the influence of the transversal section geometry of the weld chord on the life of the specimens, this work evaluated three different types of chord profiles: straight, concave, and convex. The actual welding profiles obtained through SMAW processes are similar to the convex profile, the straight profile, or to an intermediate situation between both. Figure 1 shows the three weld chord profiles defined in parametrical manner. The technical standards to calculate welded joints do not take into account the shape of the chord profile and focus on analyzing the apparently weaker weld zone, defined as chord throat. Because of this, it was decided to establish a throat of dimensions $\mathrm{h}=4 \mathrm{~mm}$ for the three chord profiles. Through control points, the contour was traced by using smooth curves and the remaining dimensions were placed in function of the size of the throat.

For the T-butt joint, A36 material plates were used with a 3/8-inch thickness, and E6013 electrodes with a 1/8-inch diameter were used for filler material. Two-pass welding was used. Main parameters of the welding regimen were $69 \mathrm{~V}$ welding arc voltage and 92 A welding current (continuous current) respectively. The average weld roughness obtained is $\mathrm{Ra}=21.56 \mu \mathrm{m}$, measured with roughness tester SJ-210 Series Mitutoyo.

The joint configuration is shown in Figure 2. The plate geometry and the welded joint are defined for high-cycling fatigue to occur when applying a completely alternating load of peak value equal to $7500 \mathrm{~N}$.

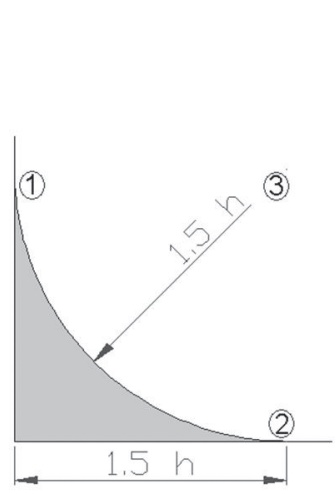

(a)

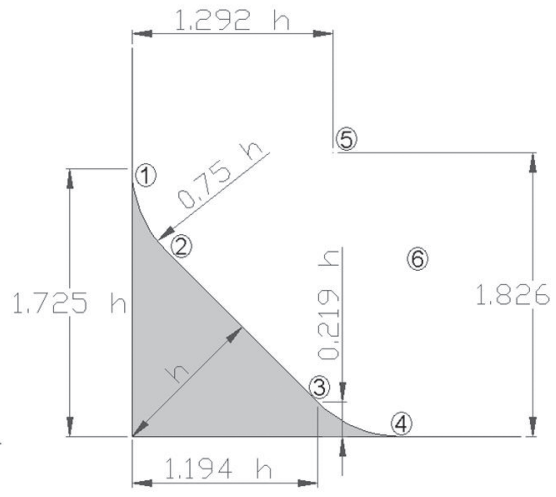

(b)

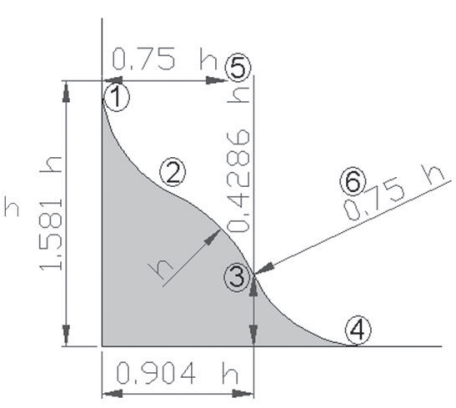

(c)

Figure 1. Parametric definition diagram of profiles used for the weld chord, with (a) concave, (b) straight, and (c) convex transversal sections (numbers in circles indicate profile construction landmarks). 


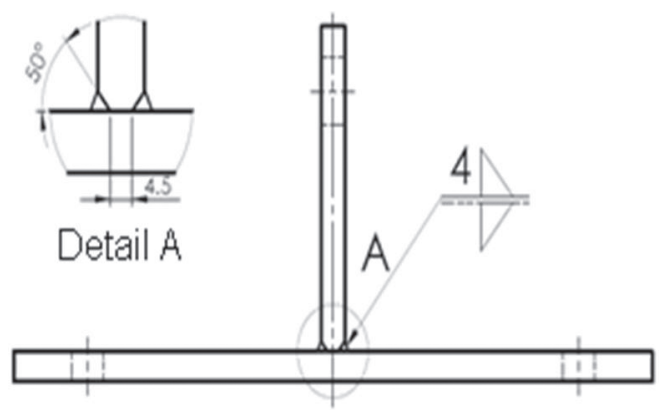

Figure 2. Geometry of the T-butt joint of two plates

The main considerations and restrictions employed in the model were:

- The plastic strain in the crack vortex was small and the Linear Elastic Fracture Mechanism could be employed.

- The filler material (E6013) and the base material (A36) are considered linear elastic and the mechanical properties were defined according to the provider's certificate of warranty.

- The initial flaw was located in the most-stressed zone and normal to the maximum main stress (in all cases this occurs for the weld chord toe).

- The flaw is a surface-type crack with 90-degree inclination with respect to the surface plane, with a four-degree angular separation of its faces, and its initial size was of $80 \mu \mathrm{m}$ [7].

- The crack propagated in the direction of lowest density of propagation energy.

- The increase of the crack between one iteration and the following does not exceed $10 \%$ of the existing crack size at the moment of iteration [8].

- Prismatic elements were used with nodes located on the vortices and in the middle of the edges; while in the front of the crack triangular prismatic elements were used.

The block diagram in Figure 3 defines the modeling procedure used. The ANSYS ${ }^{\circ}$ V10.0 Software was used to solve the unique nodes in the vicinity of the crack vortex. Each iteration in the algorithm solves the stress and strain fields and the stress intensity factors in the vicinity of the crack tip, for an increment $(\Delta \mathrm{a})$ of the crack. The algorithm stops occurs when the stress intensity factor reaches a value of the fracture toughness of the material. For this condition the crack becomes unstable and catastrophic failure occurs for the welded joint.
For crack modeling, numerous criteria that can be used appear in literature. This research used the model proposed by Paris-Erdogan, which is one of the most-often used for fatigue in the region of subcritical propagation [9-10],

$$
\frac{\mathrm{da}}{\mathrm{dN}}=\mathrm{C} \cdot \Delta \mathrm{K}_{\mathrm{eq}}^{\mathrm{m}}
$$

with $\mathrm{da} / \mathrm{dN}$ being the crack growth rate, $\Delta \mathrm{K}_{\mathrm{eq}}$ is the range of the equivalent stress intensity factor, and $\mathrm{C}$ and $\mathrm{m}$ are material property constants.

The determination of the stress intensity factors for geometries and application modes of simple loads can be done via easy to implement closed-form solutions. But when the geometries and the loads are more complicated, they induce complex fields of stress and strain in the structural component and, hence, it is recommended to use the Finite Element Method to determine said factors [11].

Moreover, the displacement correlation technique (DCT) is relatively simple to implement and offers sufficiently precise solutions for the purpose of this work. Because of this, it is employed in the crack modeling of the welded joint analyzed. To describe the stress intensity factors in the region near to the crack vortex, it is necessary to use singular elements with an additional node at a quarter of the fissure vortex.

With these singular elements, the stress intensity factors for load modes I and II can be calculated in the following manner [12],

$$
\begin{aligned}
& \mathrm{K}_{\mathrm{I}}=\frac{\mu}{\mathrm{k}+1} \cdot \sqrt{\frac{2 \pi}{\mathrm{L}}} \cdot\left\{4\left(\mathrm{v}_{\mathrm{b}}-\mathrm{v}_{\mathrm{d}}\right)+\left(\mathrm{v}_{\mathrm{e}}-\mathrm{v}_{\mathrm{c}}\right)\right\} \\
& \mathrm{K}_{\mathrm{II}}=\frac{\mu}{\mathrm{k}+1} \cdot \sqrt{\frac{2 \pi}{\mathrm{L}}} \cdot\left\{4\left(\mathrm{u}_{\mathrm{b}}-\mathrm{u}_{\mathrm{d}}\right)+\left(\mathrm{u}_{\mathrm{e}}-\mathrm{u}_{\mathrm{c}}\right)\right\}
\end{aligned}
$$

with:

$$
\begin{gathered}
\mu=\frac{E}{2(1+v)} \\
k= \begin{cases}3-4 v & \text { (plane strain) } \\
\frac{3-v}{1+v} & \text { (plane stress) }\end{cases}
\end{gathered}
$$

where:

$\mathrm{K}_{\mathrm{I}}, \mathrm{K}_{\mathrm{II}}$ : Stress intensity factors for load modes I and II, respectively $\left(\mathrm{MPa} \mathrm{m}^{1 / 2}\right)$. 


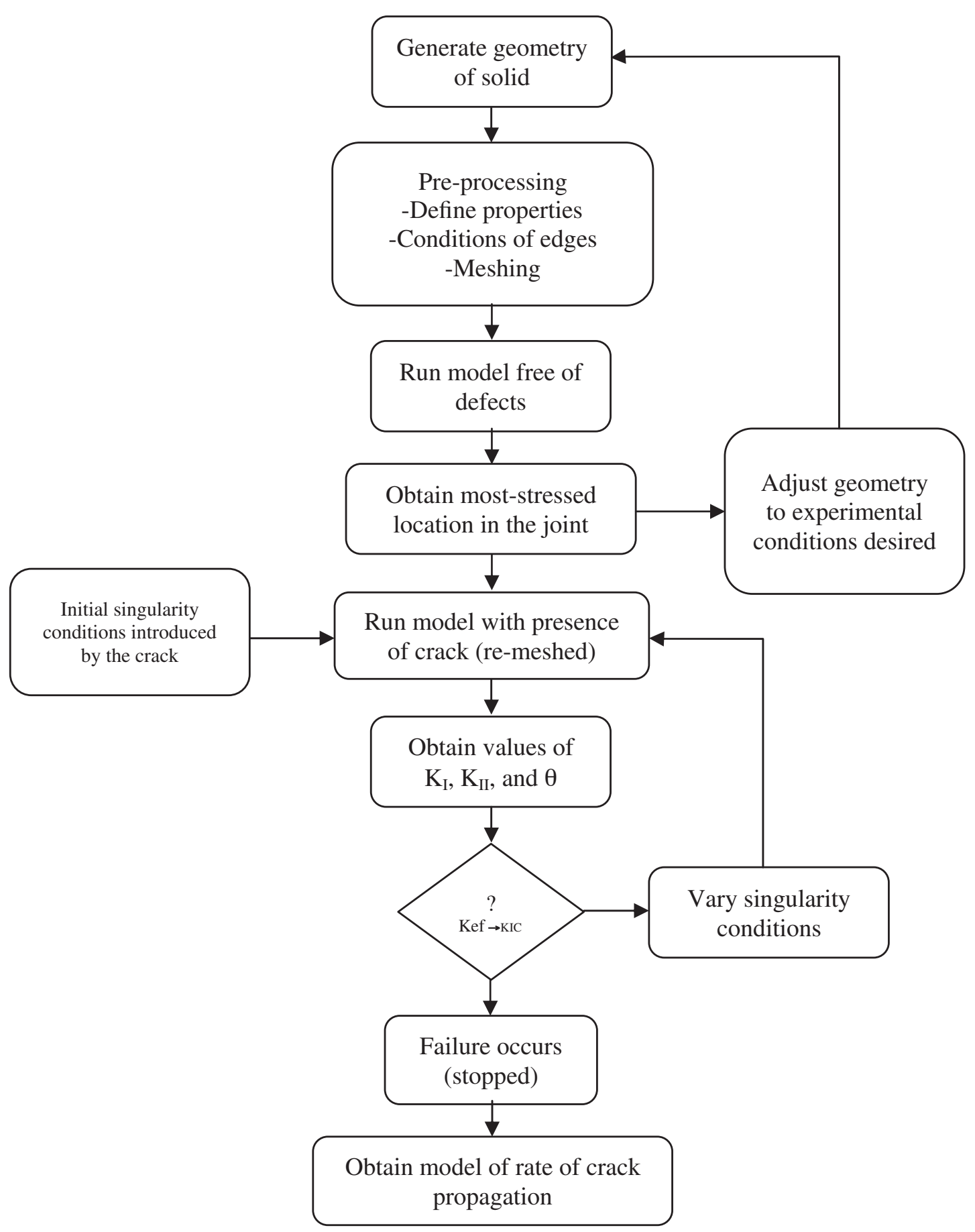

Figure 3. Block diagram showing the modeling procedure used. 
E: Material Elasticity Module (MPa).

v: Poisson's Coefficient (dimensionless).

L: Characteristic Length of the singular element $(\mathrm{mm})$.

$\left(\mathrm{u}_{\mathrm{i}} ; \mathrm{v}_{\mathrm{i}}\right)$ : Displacements in $\mathrm{x}$ and $\mathrm{y}$ respectively of the i node of the singular element (mm).

Figure 4 shows the singular elements, node arrangement, and displacements used in calculating the stress intensity factors.

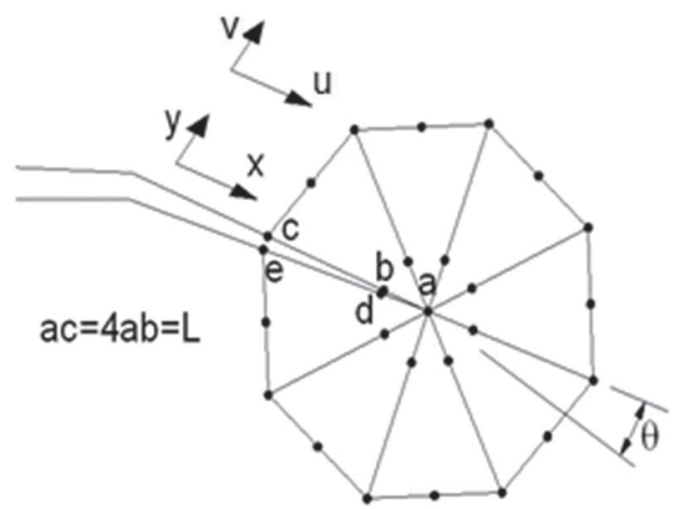

Figure 4. Arrangement of control nodes on the crack vortex.

To obtain accurate results, meshing of the component is done by observing some rules. For example, the tip of the crack must be meshed with small singular concentric elements and which do not vary in size as the crack extends. The rest of the component is meshed with quadrangular elements that provide good precision.

Several methods are available to establish crack orientation as it extends. This work used the method of strain energy density in the crack vortex (S), expressed according to (5), which establishes that the crack propagates in the direction of minimum strain energy release rate.

$$
\mathrm{S}=\mathrm{A}_{11} \mathrm{~K}_{\mathrm{I}}^{2}+2 \mathrm{~A}_{12} \mathrm{~K}_{\mathrm{I}} \mathrm{K}_{\mathrm{II}}+\mathrm{A}_{22} \mathrm{~K}_{\mathrm{II}}^{2}
$$

Where Aij are coefficients dependent on the material's elastic properties.

Once the stress intensity factors per iteration have been determined, by using (2) and (3), the dimensionless stress intensity factors, for load modes I and II respectively, are calculated through,

$$
\mathrm{F}_{\mathrm{I} / \mathrm{II}}=\frac{\mathrm{K}_{\mathrm{I} / \mathrm{II}}}{\sqrt{\pi \mathrm{a}}}
$$

Finally, the conventional procedure is presented to calculate fatigue of the joint analyzed. The results for this procedure will be employed for comparative purposes with the results of the method proposed herein. In this instance, the corrected fatigue limit $\left(\sigma_{\mathrm{e}}\right)$ was calculated by,

$$
\sigma_{\mathrm{e}}=\prod \mathrm{k}_{\mathrm{i}}\left(\frac{1}{2} \sigma_{\mathrm{ut}}\right)
$$

Where the ki factors considered affecting fatigue limit were calculated by using (8-11).

$$
\begin{gathered}
\mathrm{k}_{\mathrm{s}}=272 \sigma_{\mathrm{ut}}^{-0.995} \\
\mathrm{k}_{\mathrm{b}}=1.24 \mathrm{D}_{\mathrm{eq}}^{-0.107} \\
\mathrm{k}_{\mathrm{f}}=0.5 \text { for } \mathrm{T}-\text { butt weld joint } \\
\mathrm{k}_{\mathrm{c}}=1 \text { for } \mathrm{p}_{\mathrm{f}}=50 \%
\end{gathered}
$$

Where:

$\mathrm{k}_{\mathrm{s}}$ : Dimensionless surface factor.

$\mathrm{k}_{\mathrm{b}}$ : Dimensionless size factor.

$\mathrm{k}_{\mathrm{f}}$ : Dimensionless stress concentration factor.

$\mathrm{k}_{\mathrm{c}}$ : Dimensionless confidence factor.

$\sigma_{\mathrm{e}}$ : Corrected fatigue limit (MPa).

$\sigma_{\mathrm{ut}}$ : Ultimate tensile strength of the material of the base and filler material alloy (MPa).

$\mathrm{D}_{\text {eq }}$ : Equivalent dimension of the throat of the weld chord (mm).

According to the conventional method, the amplitude of the completely inverted effective stress supported by the section of the chord throat, is calculated by,

$$
\sigma_{\mathrm{a} \text { ef }}=\frac{\sqrt{2 \mathrm{P}}}{2 \mathrm{hW}}
$$

Where:

$\sigma_{\text {a ef: }}$ : Amplitude of the completely inverted effective stress (MPa).

W: Chord length (mm).

The number of cycles until fatigue failure $\left(\mathrm{N}_{\mathrm{f}}\right)$ calculated according to the traditional method is,

$$
\mathrm{N}_{\mathrm{f}}=\left(\frac{\sigma_{\mathrm{a} \text { ef }}}{\mathrm{A}}\right)^{(1 / \mathrm{B})}
$$


With:

$$
\mathrm{A}=\frac{\left(0.9 \sigma_{\mathrm{ut}}\right)^{2}}{\sigma_{\mathrm{e}}} ; \mathrm{B}=-\frac{1}{3} \log \left(\frac{0.9 \sigma_{\mathrm{ut}}}{\sigma_{\mathrm{e}}}\right)
$$

To validate the results of the theoretical model, a non-normalized fatigue experimental test was implemented by using an axial fatigue facility developed for this study. This is a mechanical test machine and it has a double eccentric mechanism, crank, and slider. It has two parallel assembly plates separated by a vertical distance of 500 $\mathrm{mm}$ between which the assembly devices are fixed, along with the load cell, and the specimen to be tested. Figure 5 shows (a) a view of the test process of the specimen on the equipment; and (b) the data acquisition system used to record the test variables. The experimental conditions were set thus: completely alternating $7500 \mathrm{~N}$ axial force on the specimens at $3-\mathrm{Hz}$ application frequency, and four specimens tested. The tests were carried out to weld failure. The features of the loading are monitored with a load cell. The hardware used consists in National Instruments NI-9237 card connected via USB to a PC. Software Labview Signal Express V2011 is used to record and display data.

Fabrication of the specimen was based on using a 60-mm initial plate width and after depositing the weld chords machining is carried out in both laterals until reaching a 30-mm final width. The purpose for this was to eliminate the start and end of the chord because they are likely to have defects. Specimen dimensions were verified prior to starting the test procedure. The body of the specimens was verified to discard imperfections like solidification cracks, shape distortions, and material defects using the technique of ultrasound Scan A (Olympus Epoch $\mathrm{XT}$ equipment). The specimens were also checked metrologically to guarantee the dimensions of the welded joints.

\section{RESULTS}

Figures 6 and 7 show the von Mises equivalent stresses obtained in ANSYS® V10.0 software for concave and convex chord profiles, respectively; note the effect of the stress concentration that emerges at the weld toe, which is most intense for the convex profile.

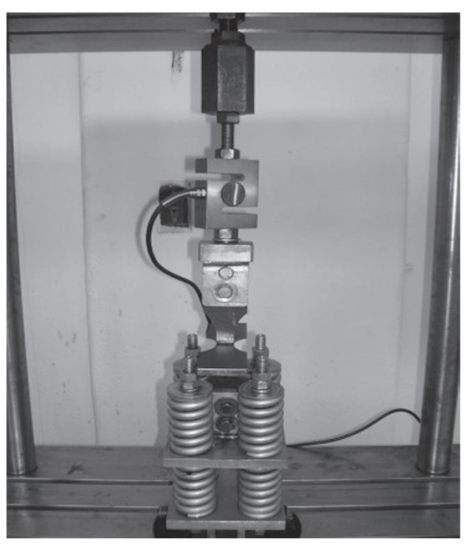

(a)

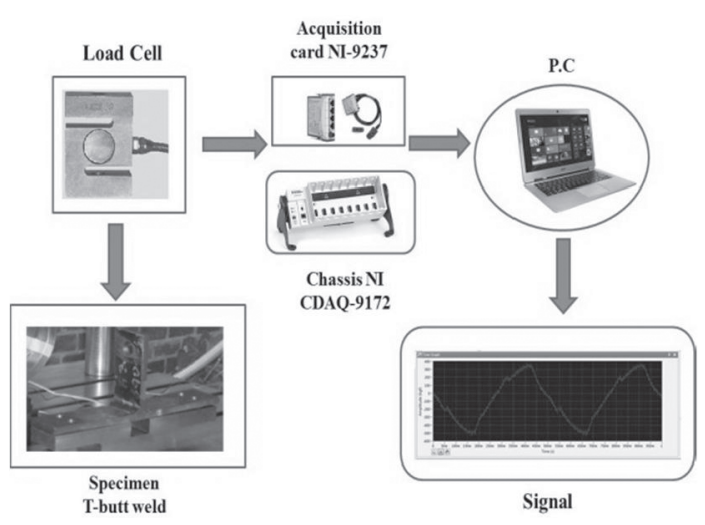

(b)

Figure 5. (a) T-welded specimen during the test process in the axial fatigue equipment; (b) data acquisition system to record test variables.

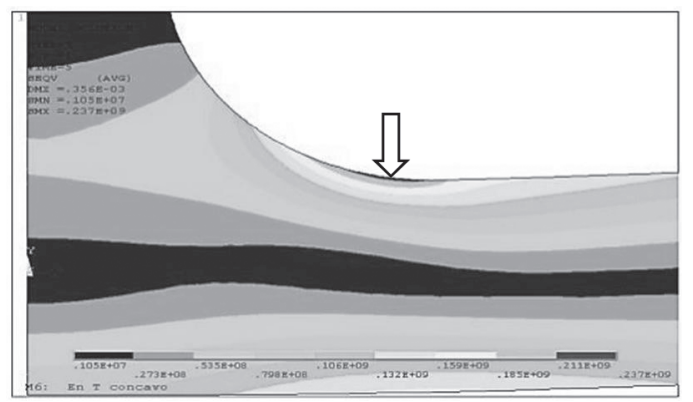

Figure 6. Von Mises equivalent stress for the weld chord concave profile.

Hence, it was decided in this welded joint to analyze the propagation of a crack at the weld toe with location on the horizontal plate. For each chord profile model, we obtained the curve 


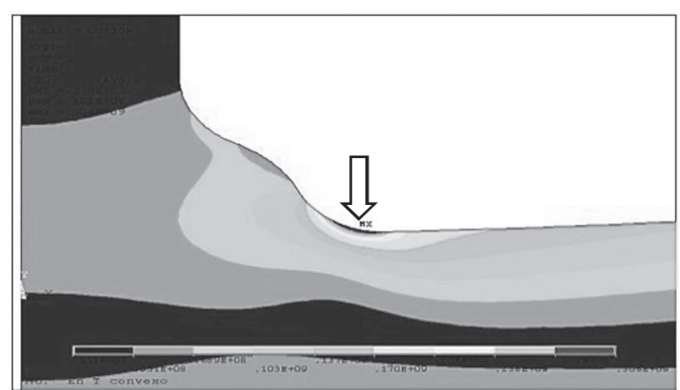

Figure 7. Von Mises equivalent stress for the weld chord convex profile.

and mathematical adjustment expression for the dimensionless stress intensity factors $\left(\mathrm{F}_{\mathrm{i}}\right)$, and the fatigue crack propagation curve $(\mathrm{a}=\mathrm{f}(\mathrm{N}))$.

From the analysis of the results, it can be noted that in all the iterations the values for $\mathrm{K}_{\mathrm{II}}$ are negligible compared to the values of $\mathrm{K}_{\mathrm{I}}$; also, the angle of crack inclination turns out to be quite small. Therefore, the stress intensity factor for load mode II may not be considered for practical effects of verifying the structural integrity.

Figure 8 shows the $F_{I}$ curves for the three types of chord transversal sections analyzed. For this geometry, only one significant difference exists in the behavior of $F_{I}$ for the region of small cracks from the concave chord section when compared with the other two chord sections analyzed.

Equation (15) shows the regression adjustment functions for the curves appearing in Figure 8. In this expression S.R.: straight section; S.CV.: concave section; and S.CX.: convex section. The correlation

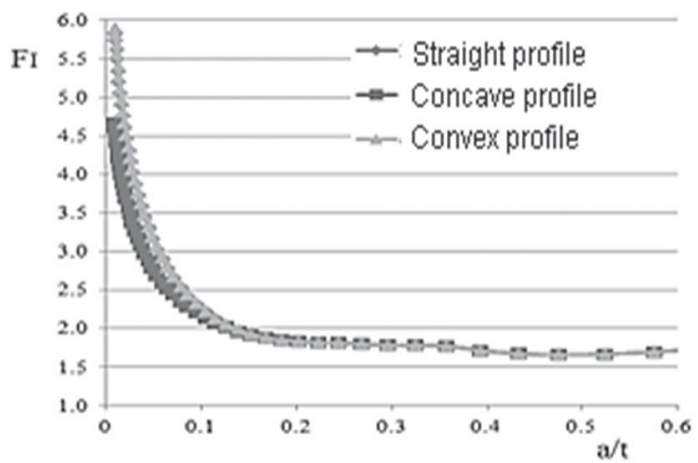

Figure 8. Dimensionless stress intensity factor FI for the surface crack on the weld toe of a welded T-butt joint. coefficients for these regression expressions are greater than 0.98 in the three cases.

$$
\mathrm{F}_{\mathrm{I}}=\left\{\begin{array}{l}
1583 \theta^{6}-4390.6 \theta^{5}+4734 \theta^{4}-2502.2 \theta^{3}+ \\
+673.7 \theta^{2}-87.269 \theta++6.1583 \text { (S.R.) } \\
1131 \theta^{6}-3135 \theta^{5}+3374.4 \theta^{4}-1777.1 \theta^{3}+ \\
+475.66 \theta^{2}-61.335 \theta+4.8845 \text { (S.CV.) } \\
1610.8 \theta^{6}-4467.9 \theta^{5}+4817.7 \theta^{4}-2546.8 \theta^{3}+ \\
+685.89 \theta^{2}-88.865 \theta+6.2367 \text { (S.CX.) }
\end{array}\right.
$$

with: $\theta=\mathrm{a} / \mathrm{t}$

Where:

$\theta$ : Dimensionless depth of crack.

a: Depth of crack (mm).

t: Thickness of plates (mm).

Figure 9 shows the stable crack propagation curves for the three types of chord transversal section analyzed. For this type of welded joint, the influence of the type of chord profile on fatigue life is not very marked, although appreciable. The chord with the concave profile has a $23.5 \%$ increased fatigue life in relation to the convex chord.

Table 1 shows a summary of the results of crack fatigue propagation for the three weld chord profiles analyzed. The failure condition was established via simultaneous analysis of fracture and plastic collapse by using a failure evaluation diagram.

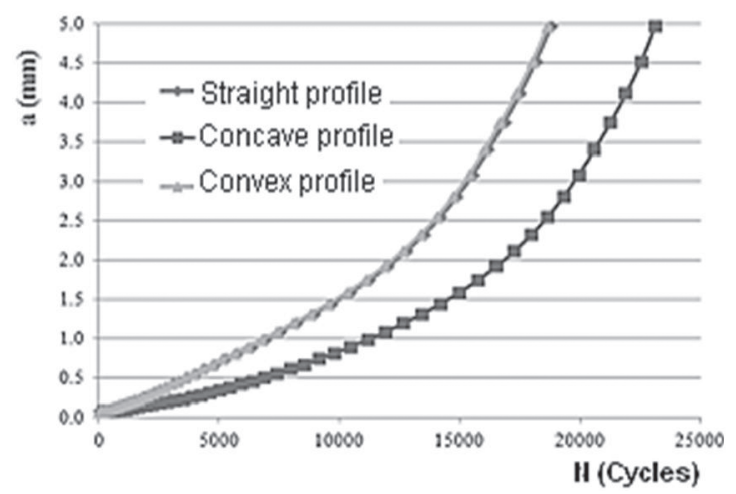

Figure 9. Stable crack propagation curves for the three types of weld chord profiles for T-butt joint.

The following presents a comparison among the results reached through the method implemented, the conventional method, and the experimental results obtained. 
Table 1. Summary of fatigue life for the three types of chord transversal section.

\begin{tabular}{|l|l|l|l|l|}
\hline \multicolumn{2}{|l|}{$\begin{array}{l}\text { Fatigue life for each type of chord } \\
\text { transverse section (cycles) }\end{array}$} & $\begin{array}{l}\text { Dimension } \\
\text { of the crack } \\
\text { for failure } \\
(\mathrm{mm})\end{array}$ & $\begin{array}{l}\text { Failure } \\
\text { mode }\end{array}$ \\
\cline { 1 - 2 } Straight & Concave & Convex & 3.7 & $\begin{array}{l}\text { Elasto- } \\
\text { plastic } \\
\text { Collapse }\end{array}$ \\
\hline
\end{tabular}

*Life values are found in application cycles of completely inverted load $(\mathrm{R}=-1)$.

The total number of specimens tested was four. With cycling-to-failure values recorded, we found the mean value, standard deviation, and confidence interval for $95 \%$ probability. The actual welding profiles obtained through SMAW processes are similar to the convex profile, the straight profile, or an intermediate situation between both; so that a better agreement should be found among the experimental results and the results for the models of convex and straight profiles.

Figure 10 shows a comparison between the method proposed herein and the experimental results. The horizontal lines show the life values obtained through the method proposed for each of the three welding profiles studied. While the insert box shows the confidence interval for the experimental results (the central horizontal line represents the mean value of fatigue life). Life prediction for the three types of chord profiles studied is between the confidence interval established experimentally. The difference between the estimated life of the straight profile and of the convex profile is small; thereby, the over thickness present in the convex profile does not influence very negatively on the resistance to

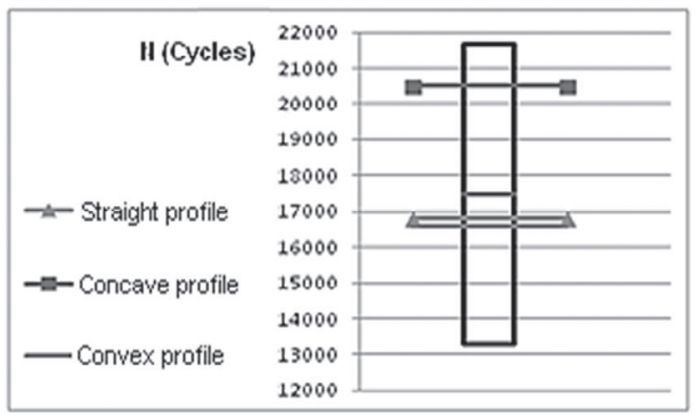

Figure 10. Comparative results among the method proposed and the experimental results. fatigue as it does, for example, in the butt-welding configuration. The concave weld profile presents the best resistance to fatigue of all the configurations analyzed. A machining method after executing the weld, which approaches the final profile geometry to a concave section, could result beneficial in increasing the joint's resistance to fatigue. Lastly, the fatigue life calculated via the conventional method yielded a cycling of $\mathrm{N}_{\mathrm{f}}>10^{6}$ cycles, which is why the life estimation through this last method underestimates the joint's real resistance capacity; unless applying the design factors the welding codes require using.

\section{CONCLUSIONS}

Very good agreement was found among the most stressed locations in the theoretical models and the zones in the specimens where fatigue cracks appeared and propagated. These locations were the toes of the welded seams, and the cracks propagated exposing their faces according to a plane very proximal to the plane of maximum main stresses. The number of cycles to fatigue failure determined through the method proposed was found within the confidence interval [13280 - 21650 cycles], calculated through the results of experimental tests. The aforementioned is coherent with the fact that the welded joints tested were not machined with the purpose of modifying the profiles of the chords; hence, having intermediate transversal shapes between the theoretical profiles of straight and convex transversal sections. It is necessary to highlight the difference existing between the regions conventionally employed to calculate and design the welded joints, and the regions that effectively endure the processes of fatigue crack initiation and propagation. The conventional calculation of fatigue life derived into a potentially dangerous underestimation. Thereby, the normalized use of design factors of magnitude three or more would be justified in traditional calculation methods. However, the lack of rigor of this last method is evident, along with the great risk it encompasses. Thus, it is shown that the conventional calculation and verification methods employed for the electric arc welded joints bear deficiencies. However, the authors of this work not underestimate in any way the use and application of existing procedure specifications and standards for welded joints. The current procedure specifications and standards have proven to be safe and reliable. 


\section{ACKNOWLEDGMENTS}

The authors wish to thank the Dirección Nacional de Investigación of the Sede Bogotá-Universidad Nacional de Colombia (research project DIB 8008044) and Universidad de Ibagué for the support offered in conducting this investigation.

\section{REFERENCES}

[1] AWS. "Design Handbook for calculating fillet weld sizes". American Welding Society. Miami, Florida. 1997.

[2] M.S. Alam. "Structural integrity and fatigue crack propagation Life assessment of welded and weld-repaired structures". Thesis South Dakota school of mines and technology. USA. 2005.

[3] M.A. Wahab and M.S. Alam. "The significance of weld imperfections and surface peening on fatigue crack propagation life of butt-welded joints". Journal of Materials Processing Technology. Vol. 153 and 154, pp. 931-937. 2004.

[4] O. Araque and N. Arzola. "State of the art in structural integrity of welded joints and crack models for structures life management". Ingeniare. Revista chilena de Ingeniería. Vol. $21 \mathrm{~N}^{\mathrm{o}}$ 2, pp. 279-292. Agosto 2013. ISSN: 0718-3305. URL: http://www.scielo. $\mathrm{cl} /$ scielo.php?script=sci_pdf\&pid=S071833052013000200011\&lng=es\&nrm=iso\& tlng=es. Fecha de consulta: 14 de agosto de 2013.
[5] N.T. Nguyen and M.A. Wahab. "The Effect of Butt Weld Geometry Parameters on Stress Intensity Factor and Fatigue Life". Computational Mechanics, Valliappan, Pulmano \& Tin-Loi (Eds). Rotterdam, pp. 883-888. 1993.

[6] X. Niu and G. Glinka. "The Weld Profile Effects on Stress Intensity Factors in Weldments". International Journal of Fracture. Vol. 35, pp. 3-20. 1987.

[7] P. Broberg. "Surface crack detection in welds using thermography". NDT\&E International. Vol. 57, pp. 69-73. 2013.

[8] M. Benachour, M. Benguediab, A. Hadjoui, F. Hadjoui and N. Benachour. "Fatigue crack growth of a double fillet weld". Computational Materials Science. Vol. 44, pp. 489-495. 2008.

[9] D.F. Socie and G.B. Marquis. "Multiaxial Fatigue". Society of Automotive Engineers, pp. 232-272. 2000.

[10] R.D. Murthy, P. Gandhi and A.G. Madhava. "A Model for Fatigue Prediction of Offshore Welded Stiffened Steel Tubular Joints Using FM Approach". International Journal of Offshore and Polar Engineering. Vol. 4, Issue 3, pp. 241-247. 1994.

[11] H. Tada, P. Paris and G.R. Irwin. "The stress analysis of cracks handbook". Del Research Corporation. St. Louis, Missouri, USA. pp. 452-620. 1973.

[12] R.S. Barsoum. "On the use of isoparametric finite elements in linear fracture mechanics". Int. J. for Numerical Methods in Engineering. Vol. 10, pp. 25-37. 1976. 